\title{
A Comparison of the Influence of Vegetation Cover on the Precision of an UAV 3D Model and Ground Measurement Data for Archaeological Investigations: A Case Study of the Lepelionys Mound, Middle Lithuania
}

\author{
Algimantas Česnulevičius *, Artūras Bautrènas, Linas Bevainis and Donatas Ovodas \\ Department of Cartography and Geoinformatics, Institute of Geosciences, Faculty of Chemistry and Geosciences, \\ Vilnius University, LT-03101 Vilnius, Lithuania; arturas.bautrenas@gf.vu.lt (A.B.); linas.bevainis@gf.vu.lt (L.B.); \\ ovodas@gmail.com (D.O.) \\ * Correspondence: algimantas.cesnulevicius@gf.vu.lt
}

Received: 10 October 2019; Accepted: 28 November 2019; Published: 2 December 2019

check for updates

\begin{abstract}
The aim of this research was to conduct a comparative analysis of the precision of ground geodetic data versus the three-dimensional (3D) measurements from unmanned aerial vehicles (UAV), while establishing the impact of herbaceous vegetation on the UAV 3D model. Low (up to $0.5 \mathrm{~m}$ high) herbaceous vegetation can impede the establishment of the anthropogenic roughness of the surface. The identification of minor surface alterations, which enables the determination of their anthropogenic origin, is of utmost importance in archaeological investigations. Vegetation cover is regarded as one of the factors influencing the identification of such minor forms of relief. The research was conducted on the Lepelionys Mound (Prienai District Municipality, Lithuania). Ground measurements were obtained using Trimble GPS, and UAV “Inspire 1" was used for taking aerial photographs. Following the data from the ground measurements and aerial photographs, large scale surface maps were drawn and the errors in the measurement of the position of the isolines were compared. The results showed that the largest errors in the positional measurements of fixed objects were conditioned by the height of grass. Grass with a height of up to $0.1 \mathrm{~m}$ resulted in discrepancies of up to $0.5 \mathrm{~m}$, whereas grass that was up to $0.5 \mathrm{~m}$ high led to discrepancies up to $1.3 \mathrm{~m}$ high.
\end{abstract}

Keywords: GPS measurement; UAV; 3D models; measurement precision

\section{Introduction}

During the initial stage of an archaeological investigation, one of the most important principles is to identify a potential object, to determine its boundaries and area. Traditionally, large-scale topographic maps and geodetic measurements are widely used during the initial stage of reconstruction.

Aerial photographs were mainly used where archaeological sites coincided with the areas covered by aerial topography and only on fragmentary basis due to their high cost. High-resolution space images have only become possible within the last decade, but they do not cover continuous areas. Moreover, high resolution photos are not always available for academic research or studies. At the beginning of the 21st century unmanned aerial vehicles, better known as drones, were employed to identify and map potential archaeological objects. They have a number of advantages which include the following characteristics: low price, high resolution, large scale, and multispectral. A very important advantage of unmanned aerial vehicles is the creation of 3D models using photogrammetric techniques. These 3D models reveal the small roughness of the surface. Such alterations in the surface serve as identifiers, when searching for potential archaeological sites. 
The issues of reliability and accuracy of aerial photographs obtained using unmanned aerial vehicles have already been addressed in studies by many academic researchers [1-21]. The use of unmanned aerial vehicles provide a fast and inexpensive way to explore ground surface and to identify objects of interest [22], however, research on assessing the precision of aerial images from unmanned aerial vehicles is scarce [23-26]. The accuracy of aerial images produced with the help of unmanned aerial vehicles (UAVs) can be affected by a number of factors, for example, altitude of flight, the image quality of the photo camera, the design of the UAV route, the methods of georeferencing, and others. An appropriate design of the UAV route ensures cruise altitude and constant aerial image coverage of the whole territory. An appropriate project for the flight and a high-quality photo camera effect the efficiency of photogrammetric processing of the images obtained. Further investigations are simplified by using the well-tested and broadly applied mathematical and photogrammetric algorithms for image processing. The problems occur while designing a 3D model of the territory captured in aerial images. The initial 3D model is created in the conditional coordinate system, which is later linked to the officially used coordinate system. The coordinates can be connected in one of the following two ways: by direct graphical connection of the position of the object in the aerial image to the coordinate system (less precise) or by linking the GPS measurements of fixed objects to the coordinates of the aerial images. The accuracy of the vertical positioning of given points is a highly important factor in designing the 3D relief models that are used for identification, analysis, and mapping of archaeological objects.

Recent research [18-32] has shown that while aiming for high accuracy of the vertical positioning of the objects, it is not enough to use a global navigation satellite system (GNSS); ground control points (GCPs) have to be applied as well. Such a combined technique allows for the design of a more accurate digital relief model (DRM), where the precision of vertical positioning of points equals $0.7 \mathrm{~cm}$.

The aim of this research is to conduct a comparative analysis of the precision of ground geodetic measurements and aerial photographs from an unmanned aerial vehicle, while establishing the positional accuracy of the identified objects. The archaeological objects of the Middle Ages in the eastern coast of the Baltic sea are often related to natural relief forms, which were modified by people while building fortifications and settlements around them [33-37]. These archaeological objects are now in forests, agricultural lands, and urbanized territories. The surface of archaeological objects in such urban territories has been exposed to significant changes or has been fully destroyed. The use of aerial images from unmanned aerial vehicles for the positional identification of archaeological objects is highly limited. Due to dense vegetation and the foliage of tall trees, the application of aerial imaging in wooded territories is restricted. The surface of archaeological objects in agricultural territories is partially extant. Therefore, aerial images can be rather efficient in seeking to identify positions of archaeological objects in meadows and woodless territories.

The narrow spectral and surface thermal analysis methods are applied for the investigation of the structural diversity of vegetation cover on the basis of UAV aerial images [38-42]. Studies have mainly focused on the influence of big ligneous plants on the mapping of surface elements, whereas the impact of low herbaceous vegetation on low forms of archaeological relief has, so far, not been exhaustively researched [43]. Our research aims to assess the quality of aerial images, ultimately seeking to design accurate digital 3D relief models for the identification of archaeological objects [44-50].

For the identification of small surface irregularities (small archaeological objects) we applied the computer program "Circle_3p", developed by the Department of Cartography and Geoinformatics, Vilnius University, applying the classical Delaunay method (author Artūras Bautrenas). The results of the study showed that this method is effective in grassy mounds.

\section{Research Object, Materials, and Methods}

The object of the research is the Lepelionys Mound, which is located in the Prienai Administrative Region of Kaunas County (Figure 1). It dates back to the second half of the first millennium. At the beginning of the second millennium a settlement was established there, covering an area of 9 hectares around the mound. The Lepelionys Mound is on the left side of the road from Vilnius to Prienai $(60 \mathrm{~km}$ 
to the west of Vilnius). The territory of the ancient settlement is on both sides of the road, but its bigger part is located on the left side. The Vilnius-Prienai road was built in the second half of the 20th century. While designing the road, the relief of the former ancient settlement was affected but some small and low relief forms of anthropogenic origin still remain, dating back to between the 9th and 12th centuries [51,52]. The main archaeological object, the Lepelionys Mound, was investigated by archaeologists in the second half of the 20th century. During these archaeological investigations the territory boundaries and the protection zone of the ancient settlement were distinguished (Figure 1).

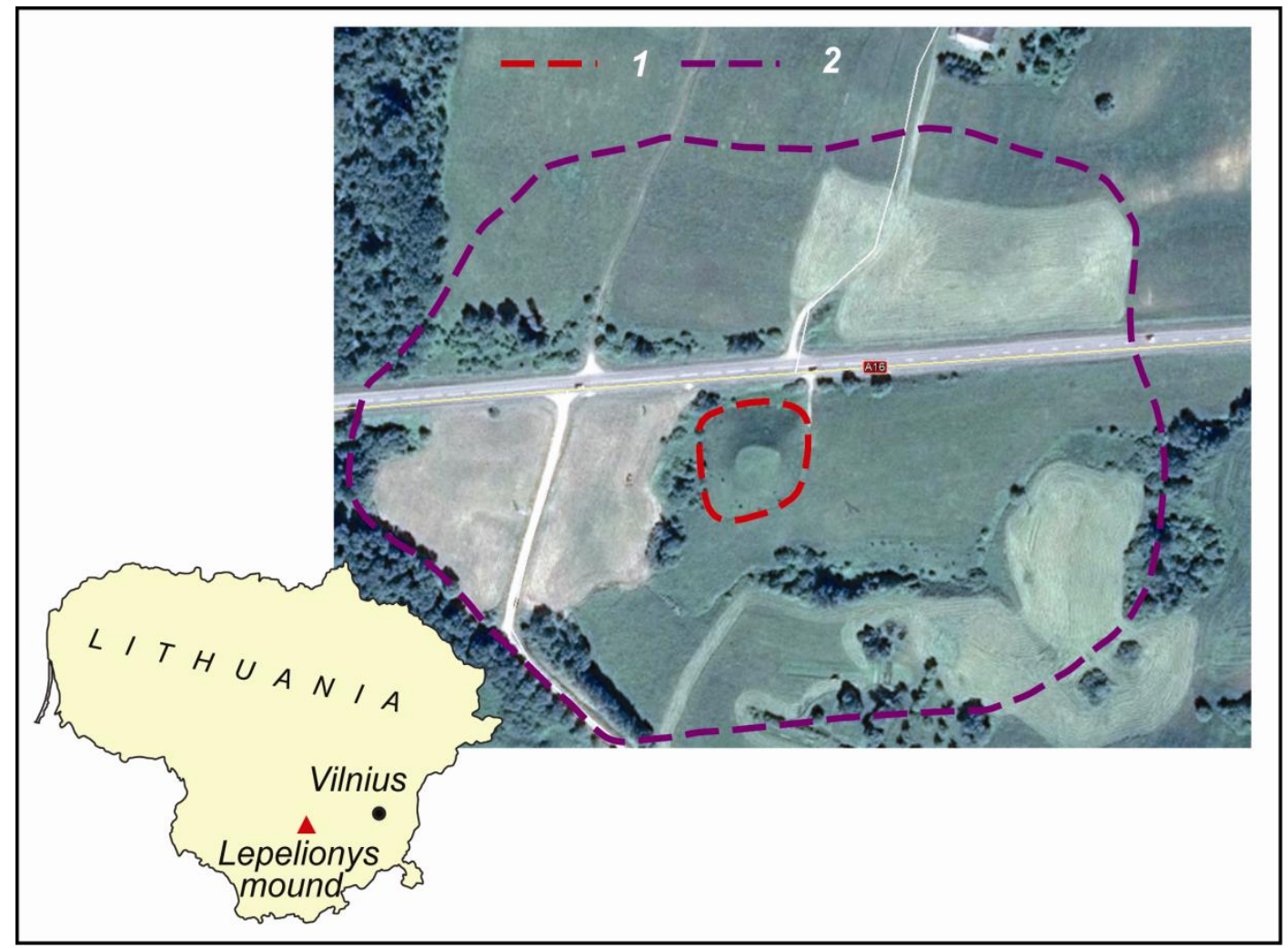

Figure 1. The location of Lepelionys Mound and the ancient settlement: (1) mound boundary and (2) ancient settlement territory boundary (according to V. Juškaitis [51]).

Ground geodetic measurements and photos taken by the camera on the unmanned aerial vehicles were applied while designing the three-dimensional relief models. Comparisons of accuracy between the UAV 3D model and the ground measurements of the Lepelionys mound were carried out twice, in August 2018 and June 2019.

Ground geodetic measurements were carried out with a Trimble R4 GPS device (measurable accuracy in favorable conditions: $\mathrm{X}, \mathrm{Y}$ is set to $\pm 8 \mathrm{~mm}$ and $\mathrm{Z}$ to $\pm 15 \mathrm{~mm}$ ) on 9 August 2018. Since the mound is in a fully open area and not covered by buildings or greenery (Figure 1), the measurements were collected with maximum accuracy. During the collection of these measurements, the coordinates of 212 characteristic ground-surface points were recorded. After analyzing the accuracy of the measured point coordinates, 179 points were mapped to the LKS-94 coordinate system (Figure 2). 


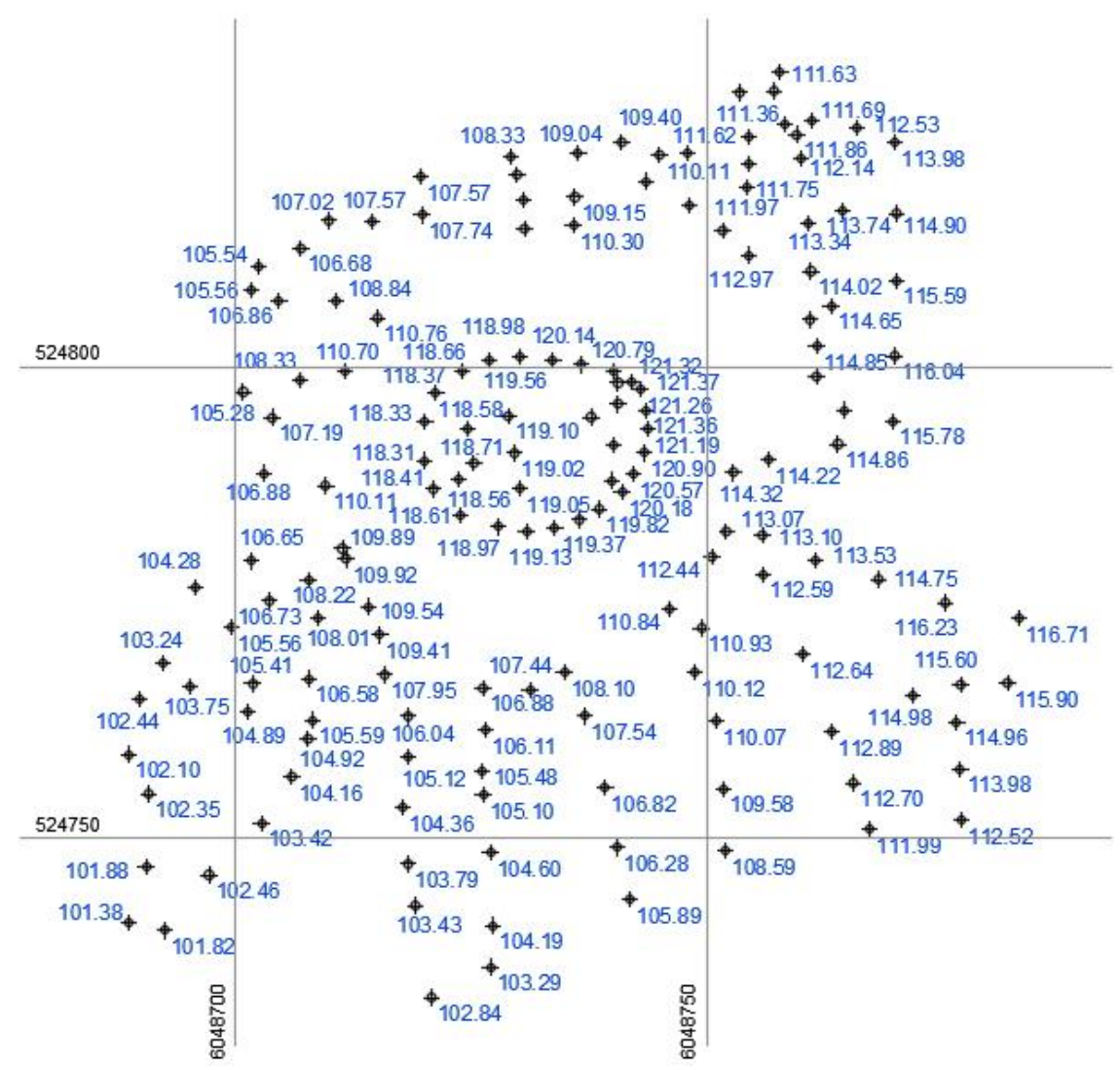

Figure 2. The selected points that were mapped to the LKS-94 coordinate system.

Since the topographic photograph can be used to estimate the accuracy of the aerial photographs, 10 ground control points (GCPs) were measured in parallel to the ground points (Figure 3).

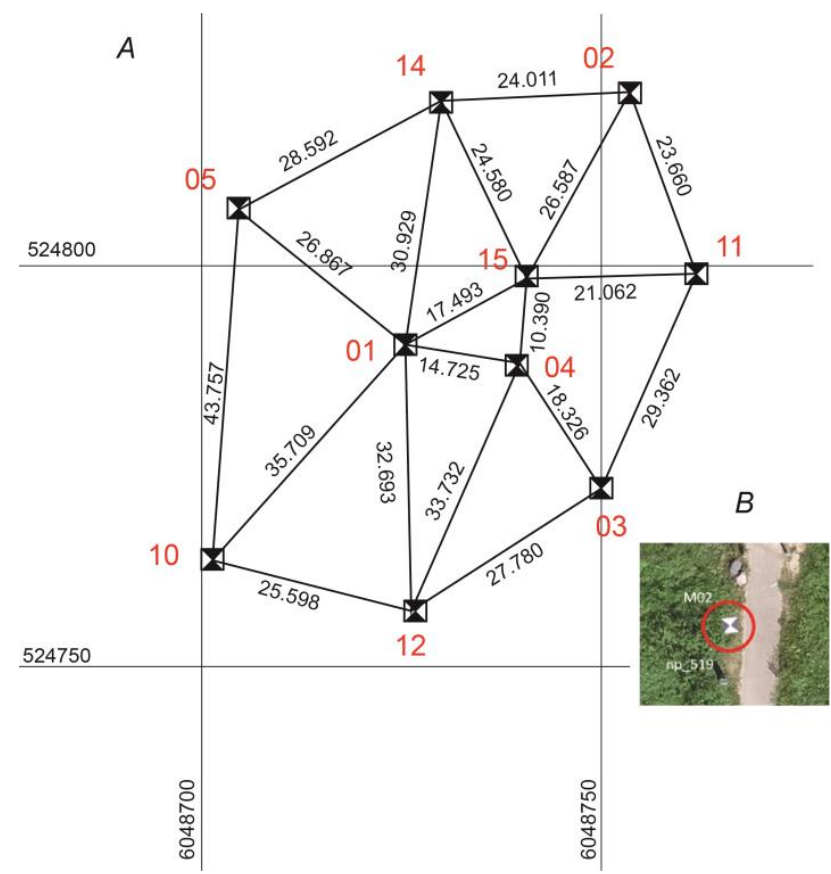

Figure 3. The ground control point marks (A) and the diagram of the ground control point (GCP) arrangement (B). The red circle defines the location of the ground mark. 
Figure 4 shows two objects, the coordinates of which were used for creating the aerial photograph model.

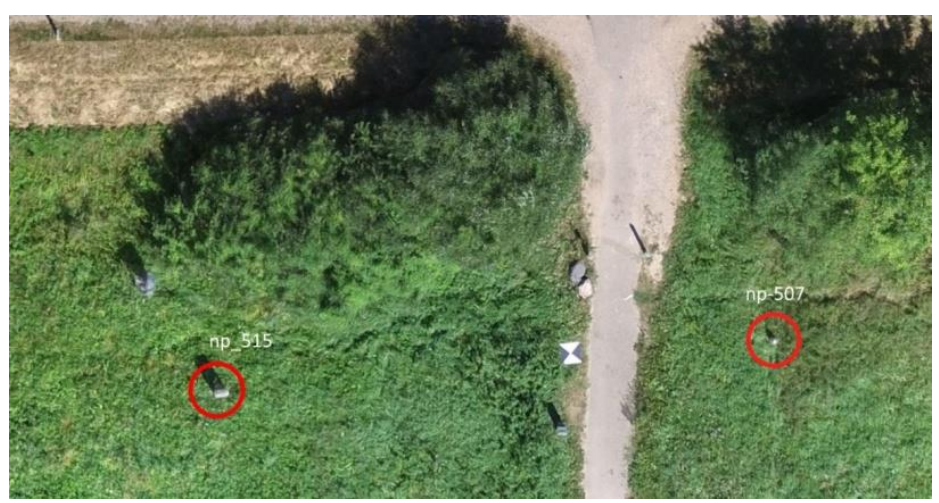

Figure 4. Examples of identified objects. The red circles define the small objects location, whose measured coordinates are used to adjust the 3D model.

The vegetation is one of the most important indicators of archaeological objects. Information on human activities is reflected in the variation of the lushness of vegetation. Homogeneous vegetation is characteristic of the investigated territory, since for several decades most of the surroundings of the mound have been used as pasture. Local differences in herbaceous vegetation in the mound surroundings over a long period of time have been predetermined by changes in the surface relief layer caused by the following human activities:

(i) Organic waste was thrown at the foot of the mound;

(ii) In the territory of the ancient settlement the ground was excavated for substructures of buildings and the soil (sediment) was poured beside the walls of the building;

(iii) The ancient settlement was surrounded by palisades, the stakes of which were driven into the ground and the excavated soil fortified the foundation of the fence;

(iv) Organic and mineral waste (ceramic fragments, bones of the animals used for food, worn out shoes, and clothes) was thrown over the palisade of the settlement.

All the aforesaid factors resulted in physical differences in the present vegetation, i.e., lusher or sparser vegetation. It is important to point out that currently there is a pasture in the former territory of the settlement, where grazing starts at the end of April and lasts until October. The whole area is grazed in this time and the anthropogenic impact on the surface was equal during photofixation in August.

The picture in Figure 5 provides a visual representation of the camera sensor and the field of view. Using the width of the camera sensor, the focal length, and the drone altitude the ground sample distance (GSD) can be calculated (Figure 5).

The equation we use to calculate the GSD is:

$$
G S D=\frac{(\text { sensors width } \times \text { altitude } \times 100)}{(\text { focal length } \times \text { image width })}
$$

Photofixation of aerial images was conducted using the unmanned aerial vehicle (UAV) INSPIRE 1. Its technical parameters are presented in Table 1. 


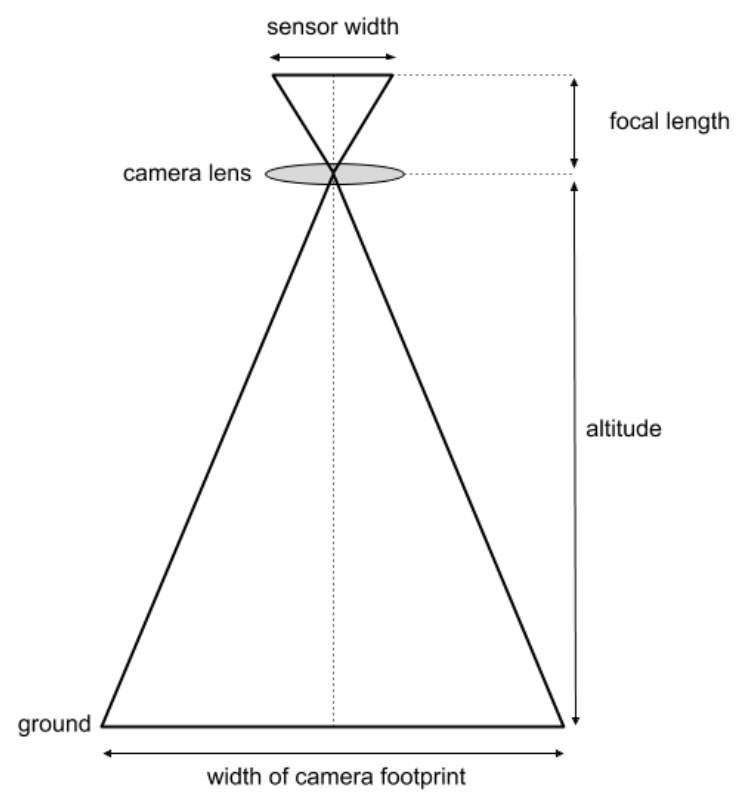

Figure 5. Visual representation of the nadir facing camera on the drone.

Table 1. The specifications of unmanned aerial vehicle (UAV) DJI Inspire1 and the RGB Zenmus X3 camera.

\begin{tabular}{|c|c|}
\hline Hovering Accuracy (GPS Mode) & Vertical: $0.5 \mathrm{~m}$; Horizontal: $2.5 \mathrm{~m}$ \\
\hline Max angular velocity & Pitch: $300^{\circ} / \mathrm{s}$; Yaw: $150^{\circ} / \mathrm{s}$ \\
\hline Max tilt angle & $35^{\circ}$ \\
\hline Max ascent and descent speed & $5 \mathrm{~m} / \mathrm{s} ; 4 \mathrm{~m} / \mathrm{s}$ \\
\hline Max speed & $22 \mathrm{~m} / \mathrm{s}$ \\
\hline Max wind speed resistance & $10 \mathrm{~m} / \mathrm{s}$ \\
\hline Max service ceiling above take-off point & $120 \mathrm{~m}$ \\
\hline Type and model & X3; FC350 \\
\hline Total and effective pixels & $12.76 \mathrm{M} ; 12.4 \mathrm{M}$ \\
\hline Max capacity & $64 \mathrm{~GB}$ \\
\hline Maximal image size & $4000 \times 3000$ \\
\hline ISO range & Photo- 100-1600; Video- 100-3200. \\
\hline The electronic shutter speed & $8 \mathrm{~s}-1 / 8000 \mathrm{~s}$ \\
\hline A field of view (FOV) & $94^{\circ}$ \\
\hline Supported file formats & Photo: JPEG, DNG; Video: MP4/MOV (MPEG-4 AVC/H.264) \\
\hline Types of electronic media & Micro SD. Maximal capacity 64 GB. Class 10 or UHS-1 \\
\hline Sensor width $(\mathrm{mm})$ & 6.17 \\
\hline Focal length (mm) & 4.55 \\
\hline Altitude (m) & 50 \\
\hline Image width & 4000 \\
\hline Image height & 3000 \\
\hline GSD (cm/pixel) & 1.695054945 \\
\hline Width (m) & 67.8021978 \\
\hline Height (m) & 50.85164835 \\
\hline
\end{tabular}


The front overlap of the pictures taken is $80 \%$ and the side overlap is $70 \%$. The "double grid" mission flight plan was used for a more detailed and accurate 3D model. The flight was made at the height of $50 \mathrm{~m}$, therefore, respectively, the GSD equals $1.7 \mathrm{~cm}$.

There were 199 photos that were processed with special photogrammetric "Pixoprocessing" software. The point cloud, the digital surface model (DSM), and the orthomosaic were obtained during this process.

The study included an assessment of the mismatches between the elevation isoline positions acquired from the ground geodetic measurements and from the aerial images from the UAVs. An associate professor of the Department of Cartography and Geoinformatics, Artūras Bautrènas, designed the computer program "Circle_3p", which employs the classical method of Delaunay and ensures a consistent systemic selection of points. Using the Delaunay triangulation method, altitude interpolation of the ground measurement points was performed and an isoline view was generated. An analogous method was used for the interpolation of the elevation of surface points and the generation of isolines using the images taken by the camera on the UAV (Figure 6). The following indicators were calculated: $\pm \mathrm{N}_{\mathrm{i}}$ which is the sequence number of the analyzed point in the positive or the negative deviation from the base (ground geodetic measurement) isoline, $\pm \Delta S_{i}$ which is the length of the perpendicular to the positive or the negative side of the analyzed point, $\pm \Delta Z_{i}$ which is the calculated correction of the overdose to the positive or the negative side, and $\pm \mathrm{D}$ which is the distance between the base (ground geodetic measurement) isoline point and the UAV isoline point.

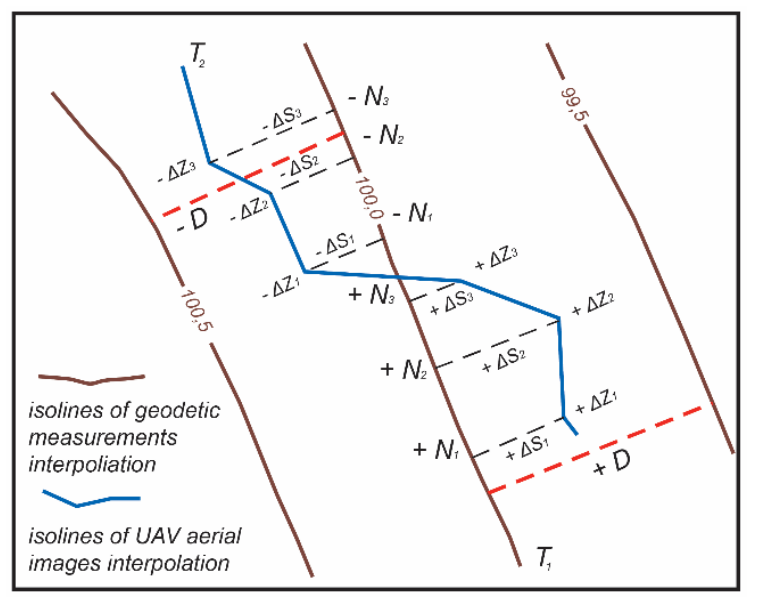

Figure 6. The scheme of elevation isoline position assessment using ground geodetic measurements and the mismatch between it and the aerial images from UAVs.

For the calculation of the deviation of the target position the following formula was used:

$$
\pm \Delta \mathrm{S}_{\mathrm{i}}=\left(\mathrm{y}_{\mathrm{Ni}}-\mathrm{y}_{\mathrm{Ti}}\right) \cos \alpha-\left(\mathrm{x}_{\mathrm{Ni}}-\mathrm{x}_{\mathrm{Ti}}\right) \sin \alpha .
$$

where $\alpha$ is the directional angle of the segment $\mathrm{N}_{\mathrm{i}}-\mathrm{N}_{\mathrm{i}+1}, \mathrm{~T}_{\mathrm{i}}$ is the number of the interpolated UAV measurement point, and $i$ is the number of the point for each fragment of the ground geodetic and UAV isolines.

As we know what the isoline step is $(0.5 \mathrm{~m})$, the distance between the horizontal $( \pm D)$ at each $\mathrm{N}_{\mathrm{i}}$ point can be calculated by geometric interpolation. The difference in height $\pm \Delta Z_{i}$ is calculated using the formula:

$$
\pm \Delta Z_{i}=\frac{ \pm h}{ \pm D_{i}} \times \pm \Delta S_{i}
$$

where $h$ is the isoline step, $D$ is the distance between the horizontal at the calculated point, and the \pm sign depends on the direction of the horizontal deviation. 


\section{Results}

\subsection{Creating a Two-Dimensional (2D) Relief Model}

In order to confidently state that the $2 \mathrm{D}$ relief model is sufficiently precise and can be used as a benchmark for estimating the models, which were made by using aerial photometric methods, the horizontals were drawn automatically in accordance with strict interpolation rules.

In order to perform the automated relief modelling, it was necessary to select pairs of measured points, among which it would be possible to calculate the exact horizontal surfaces of the relief, i.e., interpolate heights. Therefore, the Delaunay triangulation method was chosen to interpolate the heights [53].

\subsection{Drawing of a Topographic Plan}

First, the Delaunay triangulation (Figure 7) was completed among 179 selected topographic points using the program "Circle_3p". This allowed 321 triangles to be selected, among which the interpolation of the triangle vertices was performed.

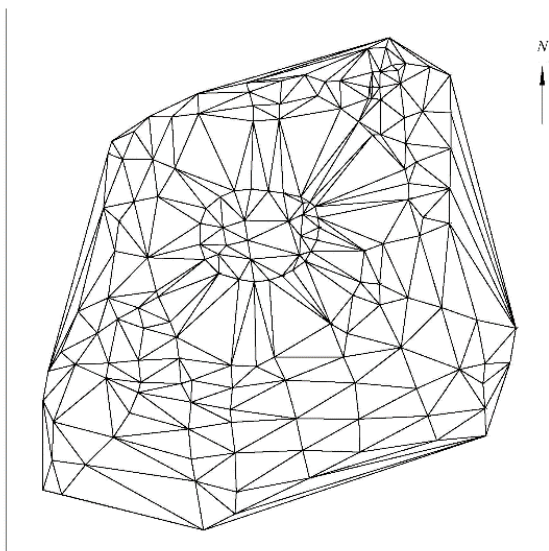

(A)

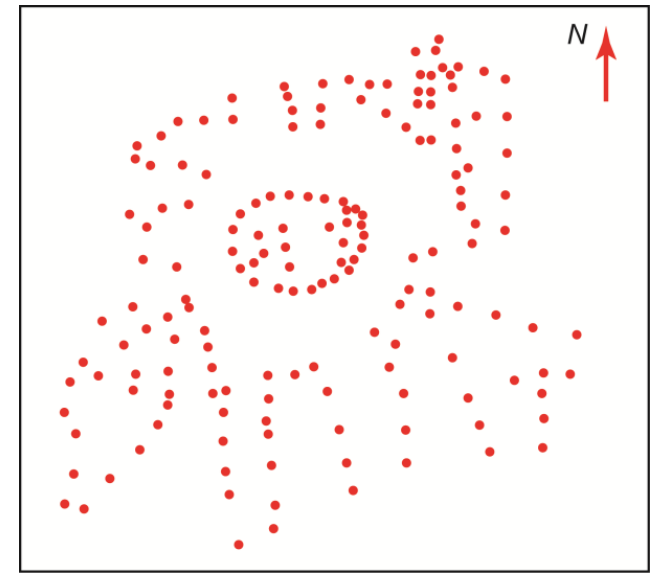

(B)

Figure 7. The Delaunay triangulation (A) among the 179 selected topographic points (B) using the program "Circle_3p".

Among these triangle vertices, horizontal interpolation was performed in the LAS07 height system using a selected step of $0.5 \mathrm{~m}$ (Figure 8). The coordinates of 1676 extra points, plotted as horizontals, were calculated during the interpolation.

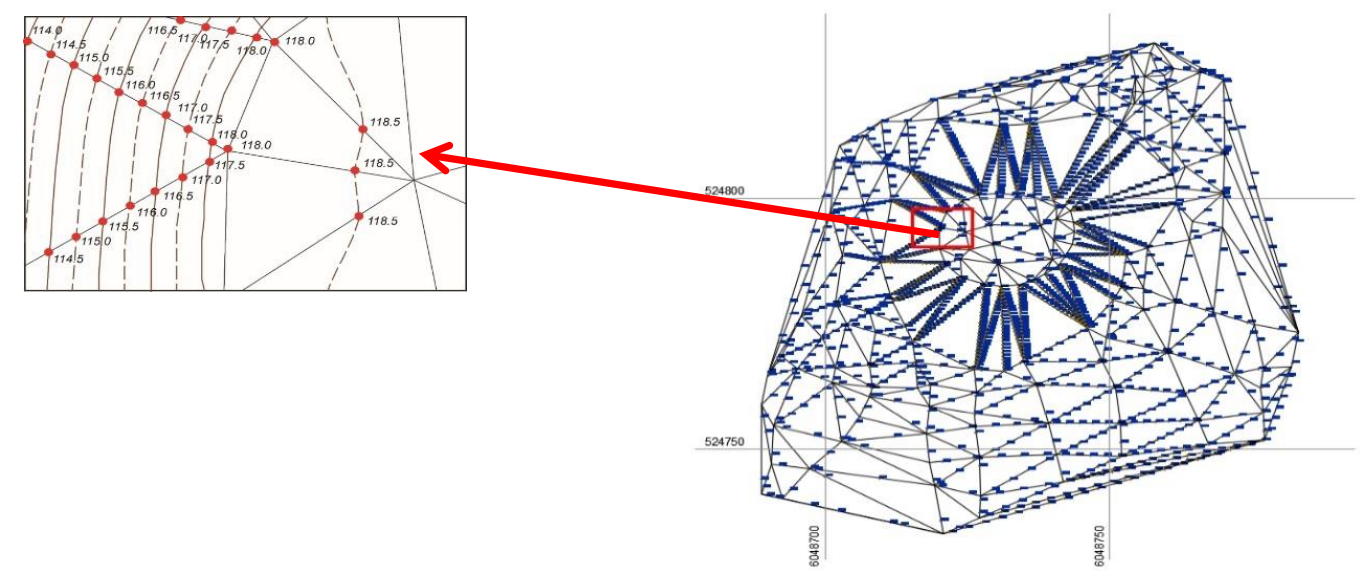

Figure 8. The interpolation among the vertices of selected triangles. 
The interpolation points were uploaded to TopoPlan (AutoCAD 2016). The horizontals were plotted using the "Spline" function (Figures 9 and 10).

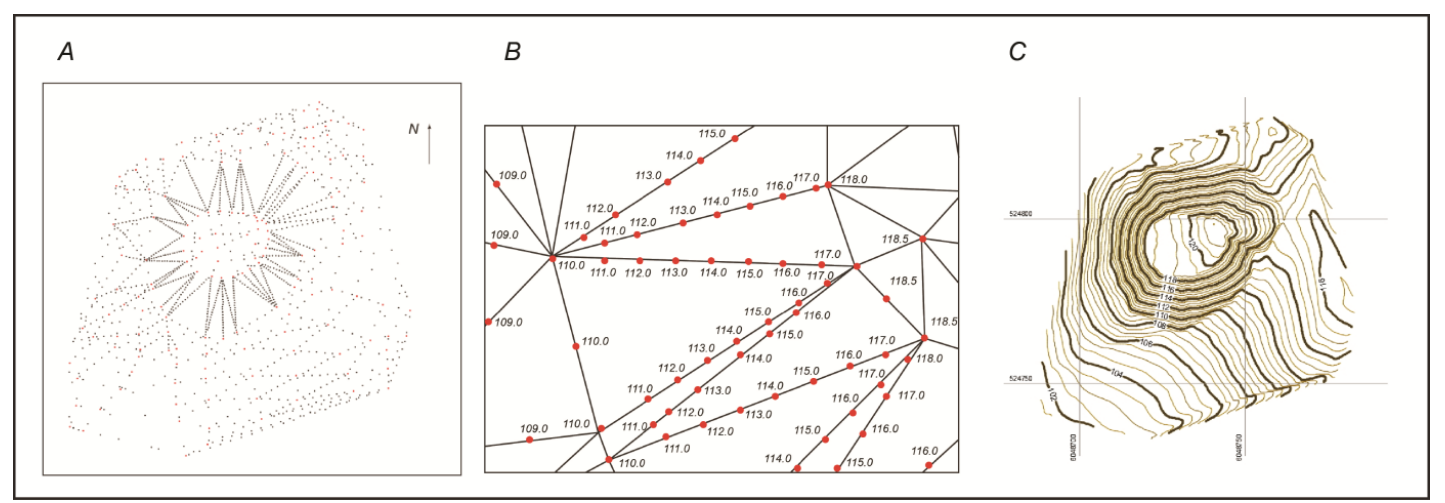

Figure 9. The points of interpolation (A), an interpolation sequence (B) and the relief isolines (C).

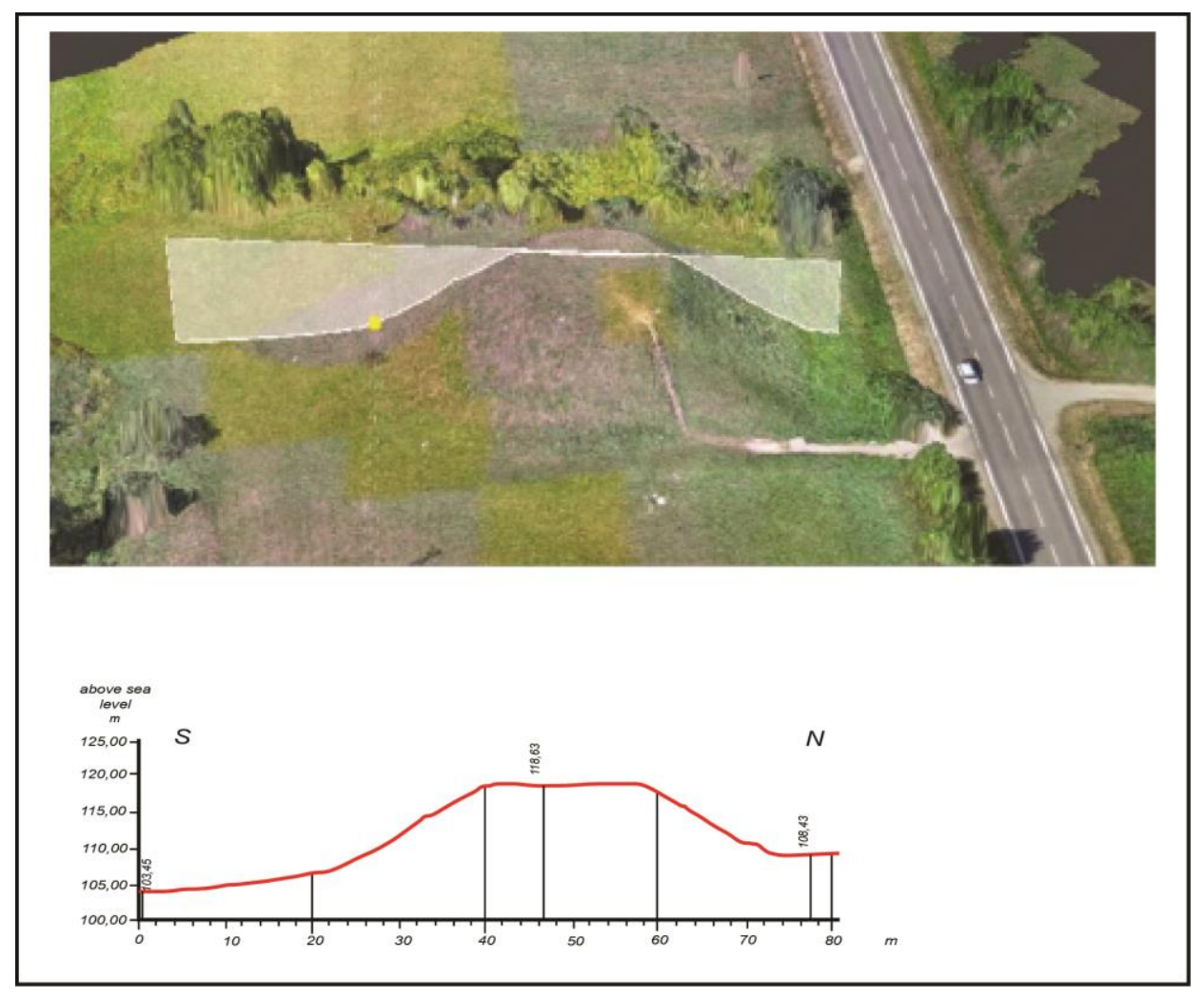

Figure 10. A cross-section of the Lepelionys Mound. The roughness in the red line indicates the remains of the former tree trunk fencing.

The cross-sections of the Lepelionys Mound were created with the help of aerial images taken by the camera on UAV, which highlighted the minor anthropogenic forms of relief on the slope of the mound, i.e., the remains of the former tree trunk wall (Figure 11). 


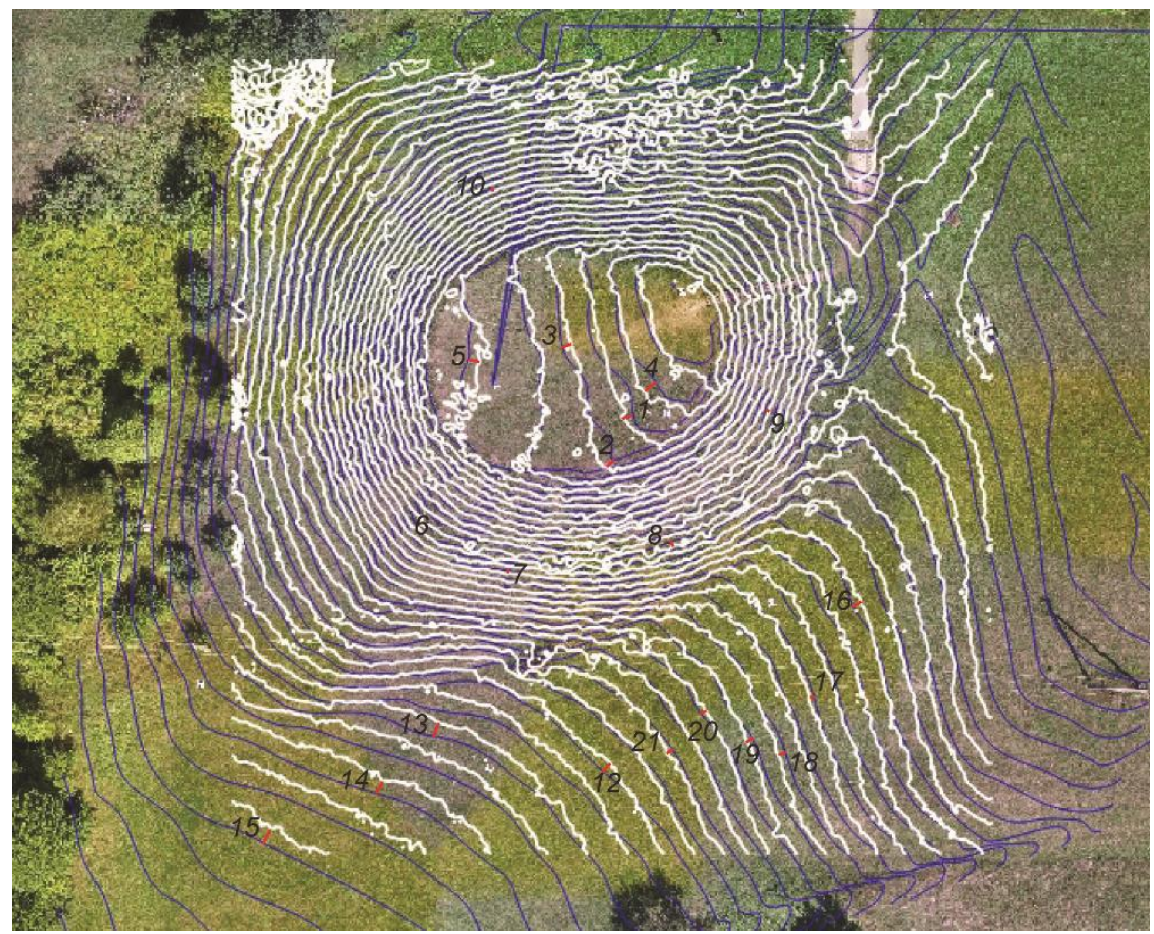

Figure 11. The variance of the equal height isolines in plane position.

\section{Discussion}

\subsection{Evaluation of the Precision of theAaerial Images}

One of the most time-consuming tasks in aerial photography is to set out the GCPs and to coordinate them. Therefore, it is necessary to find the optimal number of GCPs in order to minimize the preparatory work. It should also be possible to estimate the feasible use of coordinated stable land objects (Figure 4) instead of bearing marks, which would further simplify the preparatory work. Therefore, ten ground control points (marks) in the study area are used to estimate the accuracy of the coordinates of 10 objects in the study area (Figure 3).

In order to evaluate the accuracy of the 3D model, it was created incorporating all ten marks and the coordinates of all the objects were measured in this model. The differences between the coordinates of objects in the 3D model and the coordinates measured from the topographic image do not exceed the double (Trimble GPS) accuracy (Tables 2 and 3) for those objects that are clearly seen in the 3D model (np-508, $-515,-582$, and -587). The accuracy of the other objects is poorer due to the vegetation (grass), which complicates their identification.

The random error distribution depends on the accuracy of the object identification, and therefore the graph consists of taking the errors in absolute size in $\mathrm{mm}$.

The error analysis shows that they increase significantly when the orientation marks are fewer than five (Table 5, Figure 5), even for those objects that are visible in the 3D model (np-508, -515, -582, and -587). Therefore, it can be argued that in order to maintain the accuracy of measurements, there should be at least five orientation marks. It has been noticed that the error rate is influenced not only by the vegetation but also by the experience and thoroughness of the operator measuring the 3D model. As the precision of the well-known objects is practically unchanged (from ten to five marks), it can be argued that the 3D model should operate with maximum accuracy with five GCPs and the use of easily visible coordinated objects (Figure 12, Tables 2-5). 
Table 2. The parameters of variance of the equal height isolines in plane position.

\begin{tabular}{|c|c|c|c|}
\hline Line No. & $\begin{array}{c}\text { Variance of Equal } \\
\text { Height Isolines in Plane } \\
\text { Position, } \mathrm{m}\end{array}$ & $\begin{array}{l}\text { Slope Inclination, Degree in } \\
\text { Brackets (Mean Slope } \\
\text { Inclination Values) }\end{array}$ & Remarks \\
\hline 1 & 0.91 & 0 & The top of the mound, mown grass \\
\hline 2 & 0.71 & 0 & The top of the mound, mown grass \\
\hline 3 & 0.86 & 0 & The top of the mound, mown grass \\
\hline 4 & 0.94 & 0 & The top of the mound, mown grass \\
\hline 5 & 0.89 & 0 & The top of the mound, mown grass \\
\hline 6 & 0.60 & $30-40$ & The slope of the mound, short grass $(0.1 \mathrm{~m})$ \\
\hline 7 & 0.36 & $30-40$ & The slope of the mound, short grass $(0.1 \mathrm{~m})$ \\
\hline 8 & 0.54 & $30-40$ & The slope of the mound, short grass $(0.1 \mathrm{~m})$ \\
\hline 9 & 0.36 & $30-40$ & The slope of the mound, short grass $(0.1 \mathrm{~m})$ \\
\hline 10 & 0.34 & $30-40$ & The slope of the mound, short grass $(0.1 \mathrm{~m})$ \\
\hline 11 & 0.36 & $30-40$ & The slope of the mound, short grass $(0.1 \mathrm{~m})$ \\
\hline 12 & 0.96 & $21-26$ & The foot of the mound, high grass $(0.5 \mathrm{~m})$ \\
\hline 13 & 1.26 & $21-26$ & The foot of the mound, high grass $(0.5 \mathrm{~m})$ \\
\hline 14 & 1.09 & $21-26$ & The foot of the mound, high grass $(0.5 \mathrm{~m})$ \\
\hline 15 & 1.32 & $21-26$ & The foot of the mound, high grass $(0.5 \mathrm{~m})$ \\
\hline 16 & 0.91 & $21-26$ & The foot of the mound, high grass $(0.5 \mathrm{~m})$ \\
\hline 17 & 0.45 & $14-19$ & The foot of the mound, medium-high grass $(0.2 \mathrm{~m})$ \\
\hline 18 & 0.67 & $14-19$ & The foot of the mound, medium-high grass $(0.2 \mathrm{~m})$ \\
\hline 19 & 0.71 & 14-19 & The foot of the mound, medium-high grass $(0.2 \mathrm{~m})$ \\
\hline 20 & 0.54 & $14-19$ & The foot of the mound, medium-high grass $(0.2 \mathrm{~m})$ \\
\hline 21 & 0.63 & $14-19$ & The foot of the mound, medium-high grass $(0.2 \mathrm{~m})$ \\
\hline
\end{tabular}

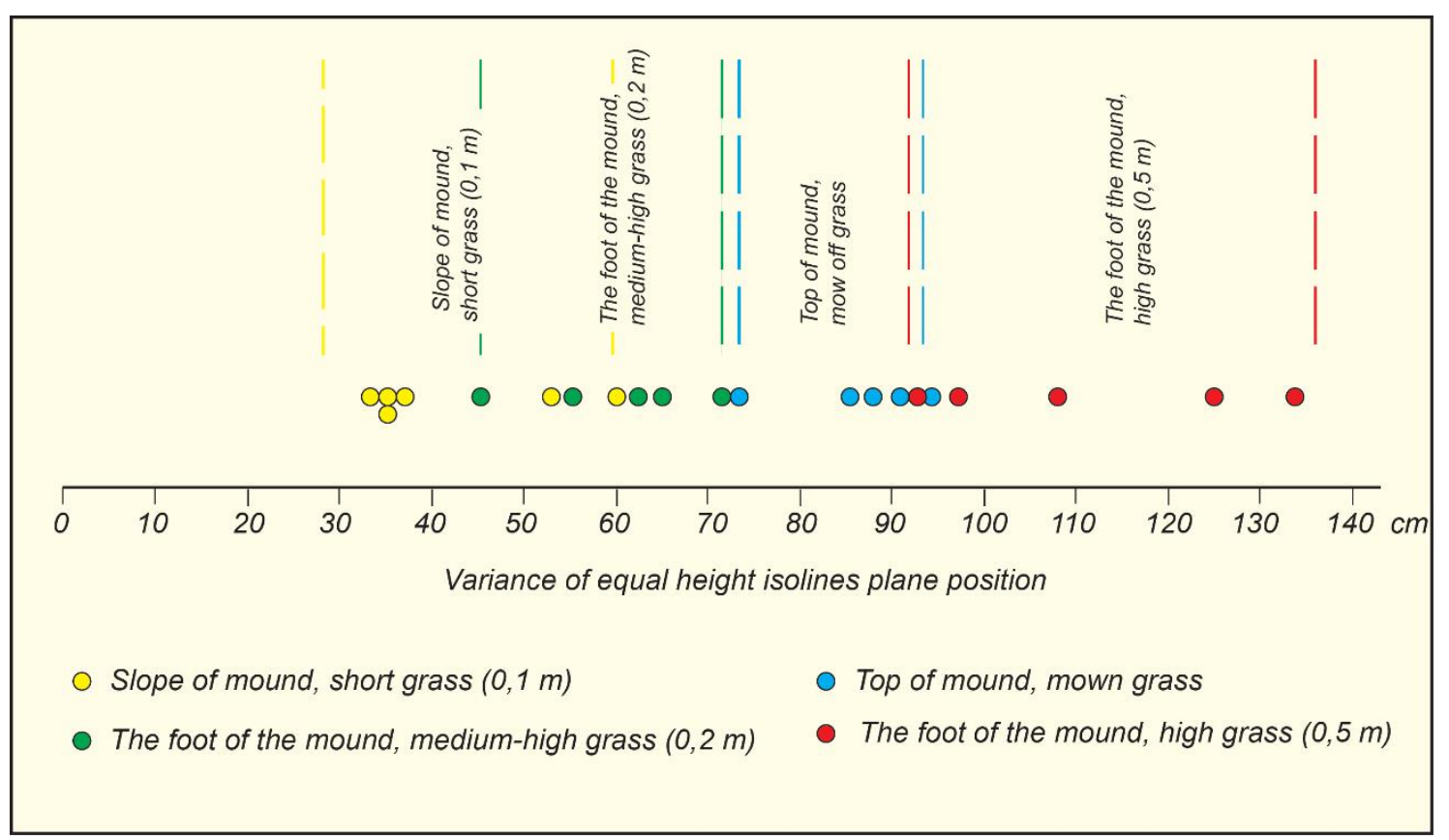

Figure 12. A diagram illustrating the parameters of variance of equal height isolines in plane position. 
Table 3. The errors of the measurements of the objects when using ten marks.

\begin{tabular}{|c|c|c|c|c|}
\hline No. & GPS & DEM & Error Size (m) & Absolute Error Size (mm) \\
\hline \multicolumn{5}{|c|}{ np-507 } \\
\hline$x$ & 6048772.162 & 6048772.216 & -0.054 & 54 \\
\hline $\mathrm{Y}$ & 524809.995 & 524810.072 & -0.077 & 77 \\
\hline $\mathrm{Z}$ & 112.138 & 112.212 & -0.074 & 74 \\
\hline \multicolumn{5}{|c|}{ np-508 } \\
\hline$x$ & 6048771.963 & 6048771.971 & -0.008 & 8 \\
\hline $\mathrm{Y}$ & 524810.078 & 524810.066 & 0.012 & 12 \\
\hline $\mathrm{Z}$ & 112.757 & 112.785 & -0.028 & 28 \\
\hline \multicolumn{5}{|c|}{ np-515 } \\
\hline$x$ & 6048774.378 & 6048774.393 & -0.015 & 15 \\
\hline $\mathrm{Y}$ & 524804.426 & 524804.440 & -0.014 & 14 \\
\hline $\mathrm{Z}$ & 111.620 & 111.644 & -0.024 & 24 \\
\hline \multicolumn{5}{|c|}{ np-522 } \\
\hline$x$ & 6048769.132 & 6048769.230 & -0.098 & 98 \\
\hline $\mathrm{Y}$ & 524803.655 & 524803.700 & -0.045 & 45 \\
\hline $\mathrm{Z}$ & 111.896 & 111.940 & -0.044 & 44 \\
\hline \multicolumn{5}{|c|}{ np-530 } \\
\hline$x$ & 6048769.708 & 6048769.740 & -0.032 & 32 \\
\hline $\mathrm{Y}$ & 524793.519 & 524793.562 & -0.043 & 43 \\
\hline $\mathrm{Z}$ & 110.071 & 110.140 & -0.069 & 69 \\
\hline \multicolumn{5}{|c|}{ np-560 } \\
\hline$x$ & 6048716.410 & 6048716.452 & -0.042 & 42 \\
\hline $\mathrm{Y}$ & 524751.812 & 524751.892 & -0.080 & 80 \\
\hline $\mathrm{Z}$ & 105.409 & 105.368 & 0.041 & 41 \\
\hline \multicolumn{5}{|c|}{ np-582 } \\
\hline$x$ & 6048712.964 & 6048712.978 & -0.014 & 14 \\
\hline $\mathrm{Y}$ & 524768.387 & 524768.400 & -0.013 & 13 \\
\hline $\mathrm{Z}$ & 106.038 & 106.006 & 0.032 & 32 \\
\hline \multicolumn{5}{|c|}{ np-586 } \\
\hline$X$ & 6048692.869 & 6048692.835 & 0.034 & 34 \\
\hline $\mathrm{Y}$ & 524769.123 & 524769.100 & 0.023 & 23 \\
\hline $\mathrm{Z}$ & 103.427 & 103.394 & 0.033 & 33 \\
\hline \multicolumn{5}{|c|}{ np-587 } \\
\hline$x$ & 6048692.729 & 6048692.734 & -0.005 & 5 \\
\hline $\mathrm{Y}$ & 524769.143 & 524769.154 & -0.011 & 11 \\
\hline Z & 104.131 & 104.107 & 0.024 & 24 \\
\hline \multicolumn{5}{|c|}{ np-596 } \\
\hline$x$ & 6048715.725 & 6048715.685 & 0.040 & 40 \\
\hline $\mathrm{Y}$ & 524781.260 & 524781.290 & -0.030 & 30 \\
\hline $\mathrm{Z}$ & 107.443 & 107.399 & 0.044 & 44 \\
\hline
\end{tabular}


Table 4. The absolute errors of objects when a 3D model is made on the basis of 10 marks with, ground control points.

\begin{tabular}{cccc}
\hline \multicolumn{5}{c}{ Absolute Error (mm) } \\
\hline Point No. & $\mathbf{X}$ & $\mathbf{Y}$ & $\mathbf{Z}$ \\
\hline $\mathrm{np}-507$ & 54 & 77 & 74 \\
\hline $\mathrm{np}-508$ & 8 & 12 & 28 \\
\hline $\mathrm{np}-515$ & 15 & 14 & 24 \\
\hline $\mathrm{np}-522$ & 98 & 45 & 44 \\
\hline $\mathrm{np}-530$ & 32 & 43 & 69 \\
\hline $\mathrm{np}-560$ & 42 & 80 & 41 \\
\hline $\mathrm{np}-582$ & 14 & 13 & 32 \\
\hline $\mathrm{np}-586$ & 34 & 23 & 33 \\
\hline $\mathrm{np}-587$ & 5 & 11 & 24 \\
\hline $\mathrm{np}-596$ & 40 & 30 & 44 \\
\hline
\end{tabular}

Table 5. A comparison of the absolute errors when different numbers of ground control points are used for a precise calculation. Values are in $\mathrm{mm}$.

\begin{tabular}{ccccccccccccc}
\hline Point No. & \multicolumn{3}{c}{ 3 Marks } & \multicolumn{3}{c}{ 4 Marks } & \multicolumn{3}{c}{ 5 Marks } & \multicolumn{3}{c}{ 7 Marks } \\
\hline & $\mathbf{x}$ & $\mathbf{y}$ & $\mathbf{z}$ & $\mathbf{x}$ & $\mathbf{y}$ & $\mathbf{z}$ & $\mathbf{x}$ & $\mathbf{y}$ & $\mathbf{z}$ & $\mathbf{x}$ & $\mathbf{y}$ & $\mathbf{z}$ \\
\hline $\mathrm{np}-507$ & 402 & 608 & 514 & 309 & 194 & 263 & 56 & 80 & 51 & 48 & 70 & 73 \\
\hline $\mathrm{np}-508$ & 86 & 105 & 56 & 36 & 42 & 42 & 11 & 12 & 26 & 10 & 9 & 19 \\
\hline $\mathrm{np}-515$ & 175 & 193 & 64 & 78 & 14 & 10 & 15 & 8 & 25 & 13 & 16 & 26 \\
\hline $\mathrm{np}-522$ & 95 & 145 & 574 & 48 & 33 & 254 & 95 & 56 & 57 & 88 & 39 & 49 \\
\hline $\mathrm{np}-530$ & 954 & 657 & 1419 & 692 & 170 & 164 & 48 & 46 & 52 & 37 & 38 & 55 \\
\hline $\mathrm{np}-560$ & 400 & 492 & 194 & 387 & 308 & 406 & 45 & 84 & 48 & 43 & 78 & 47 \\
\hline $\mathrm{np}-582$ & 102 & 266 & 88 & 56 & 32 & 39 & 16 & 11 & 28 & 11 & 15 & 29 \\
\hline $\mathrm{np}-586$ & 729 & 371 & 803 & 524 & 498 & 527 & 35 & 25 & 31 & 30 & 28 & 27 \\
\hline $\mathrm{np}-587$ & 109 & 145 & 188 & 64 & 75 & 84 & 17 & 14 & 26 & 9 & 16 & 22 \\
\hline $\mathrm{np}-596$ & 701 & 398 & 239 & 471 & 480 & 341 & 42 & 32 & 46 & 45 & 33 & 43 \\
\hline
\end{tabular}

As seen in Table 3, the random error distribution depends on the accuracy of the object identification. Similarly, the absolute errors of objects have been calculated for the 3D models with different number of ground control points (Tables 4 and 5).

\subsection{Evaluation of the Influence of Vegetation Covers}

In 2019, a comparison of the Lepelionys mound surface isolines obtained using the UAV 3D model or the ground measurements showed that there are significant deviations in the plane and height positions between the two. The comparison was carried out in different vegetation height zones (Figure 13). At the top of the mound, where the grass was mown and its height was only 1 to $2 \mathrm{~cm}$, the maximum discrepancies between the UAV 3D model and the ground measurement isolines were $0.75 \mathrm{~m}$ for the plane position and $0.42 \mathrm{~m}$ for the height. On the slopes of the mound, where the height of the grass was between 5 and $10 \mathrm{~cm}$, the maximum discrepancies between the plane position of the isolines were up to $0.41 \mathrm{~m}$, and up to $0.42 \mathrm{~m}$ for the height. At the foot of the mound, where the height of the unheated grass was 60 to $100 \mathrm{~cm}$, the maximum discrepancies between the plane position of the 
isolines reached $6.63 \mathrm{~m}$, and up to $0.77 \mathrm{~m}$ for the height. The results of the discrepancies between the plane position of the isolines and their height are presented in Table 6.

The sharpness and contrast in aerial images are both becoming important issues for the use of UAV aerial imagery. Aerial image contrast problems occur in areas that fall under the shadow of trees or rough terrain on a sunny day. In this study, the image contrast of the aerial photographs was adjusted and, where necessary, increased. During the 2018 photofixation, the western and southwestern parts of the mound slope were in shadow. To highlight the terrain microforms in parts of the image on the southwest slope we used the brightness/contrast, shadows/highlights, color balance, hue/saturation, and photo files tools in Adobe Photoshop software.

The comparison of the large-scale maps of the Lepelionys mound surface created using the UAV $3 \mathrm{D}$ model or by using the ground topographic measurements, shows that the plane position of the isolines in the 3D model is highly micro-sinuous. This is due to the methods of isoline interpolation applied in the UAV 3D model, i.e., the calculation of the interfaces between multiple point pairs (about seven million pixel pairs) creates the non-continuous isolines.

Three-dimensional terrain modelling using UAV aerial imagery is currently expanding. The wider application of collaborative mapping initiatives in archaeology [54-56] will lead to an increasing use of nonprofessional UAV aerial imagery to identify undefined and unexplored archaeological sites from the 19 th to the early 20th century.

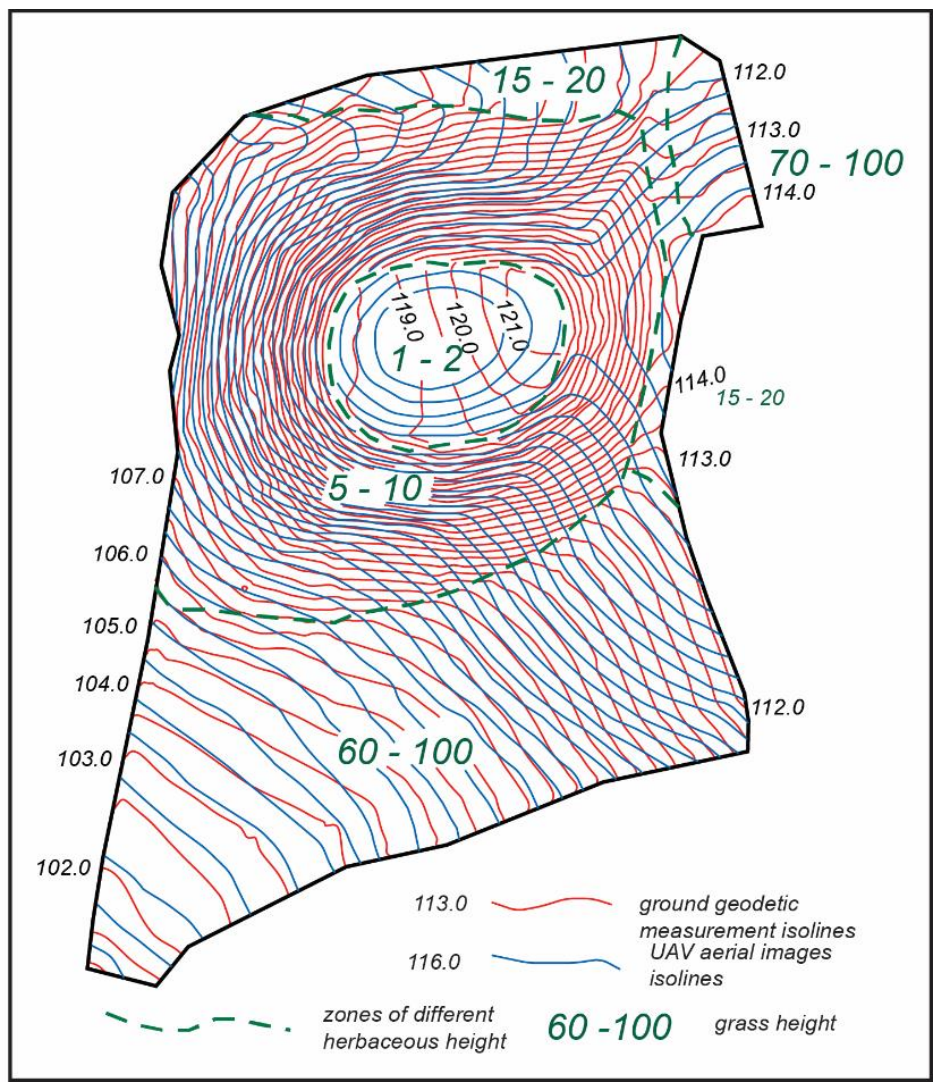

Figure 13. The zones of different herbaceous height on the Lepelionys mound. 
Table 6. The deviation between the ground measurement and the UAV isoline plane and height positions (data from June 2019).

\begin{tabular}{|c|c|c|c|c|c|c|c|c|c|c|c|}
\hline \multirow[t]{2}{*}{ Isoline Height } & \multicolumn{2}{|c|}{$\begin{array}{l}\text { Number of } \\
\text { Deviation }^{\text {a }}\end{array}$} & \multicolumn{2}{|c|}{$\begin{array}{c}\text { Maximum } \\
\text { Plane } \\
\text { Deviation, } \mathrm{m}^{\mathrm{b}}\end{array}$} & \multicolumn{2}{|c|}{$\begin{array}{l}\text { Average of } \\
\text { Plane } \\
\text { Deviation, } \mathrm{m}^{\mathrm{c}}\end{array}$} & \multicolumn{2}{|c|}{$\begin{array}{c}\text { Maximum of } \\
\text { Height } \\
\text { Deviation, } m\end{array}$} & \multicolumn{2}{|c|}{$\begin{array}{c}\text { Average of } \\
\text { Height } \\
\text { Deviation, } \mathrm{m}\end{array}$} & \multirow[t]{2}{*}{ Proportional Deviation $^{f}$} \\
\hline & - & + & - & + & - & + & - & + & - & + & \\
\hline \multicolumn{12}{|c|}{ The foot of the mound. Height of the grass was $60-100 \mathrm{~cm}$} \\
\hline 102.00 & 138 & 232 & 0.619 & 1.569 & 0.269 & 0.556 & -0.109 & +0.117 & -0.051 & +0.038 & +0.005 \\
\hline 102.50 & 741 & 399 & 6.653 & 2.527 & 1.539 & 0.834 & -0.338 & +0.214 & -0.091 & +0.071 & -0.034 \\
\hline 103.00 & 449 & 632 & 5.791 & 2.116 & 0.961 & 0.864 & -0.778 & +0.216 & -0.110 & +0.085 & +0.004 \\
\hline 103.50 & 377 & 431 & 3.950 & 1.663 & 0.569 & 0.698 & -0.480 & +0.186 & -0.064 & +0.079 & +0.012 \\
\hline 104.00 & 732 & 635 & 1.355 & 2.162 & 0.497 & 0.765 & -0.167 & +0.213 & -0.064 & +0.081 & +0.003 \\
\hline 104.50 & 882 & 863 & 2.301 & 1.822 & 0.787 & 0.569 & -0.277 & +0.293 & -0.086 & +0.080 & -0.004 \\
\hline 105.00 & 877 & 608 & 1.720 & 1.726 & 0.577 & 0.566 & -0.190 & +0.245 & -0.063 & +0.091 & 0.000 \\
\hline 105.50 & 744 & 631 & 1.693 & 1.463 & 0.539 & 0.446 & -0.199 & +0.271 & -0.074 & +0.075 & -0.005 \\
\hline 106.00 & 536 & 356 & 1.629 & 0.902 & 0.449 & 0.276 & -0.233 & +0.139 & -0.066 & +0.048 & -0.021 \\
\hline 106.50 & 532 & 222 & 1.534 & 0.513 & 0.420 & 0.197 & -0.282 & +0.120 & -0.077 & +0.043 & -0.042 \\
\hline 107.00 & 318 & 251 & 0.771 & 0.959 & 0.310 & 0.293 & -0.197 & +0.179 & -0.074 & +0.059 & -0.016 \\
\hline 107.50 & 258 & 254 & 0.518 & 0.818 & 0.214 & 0.225 & -0.126 & +0.176 & -0.047 & +0.048 & +0.000 \\
\hline 108.00 & 203 & 303 & 0.681 & 0.799 & 0.265 & 0.253 & -0.182 & +0.183 & -0.066 & +0.060 & +0.009 \\
\hline 108.50 & 70 & 382 & 0.355 & 0.969 & 0.127 & 0.330 & -0.109 & +0.174 & -0.037 & +0.062 & +0.047 \\
\hline 109.00 & 416 & 242 & 1.021 & 0.508 & 0.401 & 0.135 & -0.174 & +0.147 & -0.075 & +0.040 & -0.033 \\
\hline 109.50 & 374 & 319 & 1.736 & 0.700 & 0.469 & 0.254 & -0.406 & +0.163 & -0.115 & +0.059 & -0.035 \\
\hline 110.00 & 212 & 305 & 0.776 & 0.415 & 0.250 & 0.166 & -0.167 & +0.090 & -0.064 & +0.036 & -0.005 \\
\hline 110.50 & 344 & 189 & 1.251 & 0.449 & 0.322 & 0.132 & -0.238 & +0.103 & -0.066 & +0.030 & -0.032 \\
\hline 111.00 & 449 & 336 & 1.401 & 0.575 & 0.412 & 0.211 & -0.298 & +0.199 & -0.093 & +0.064 & -0.026 \\
\hline 111.50 & 451 & 361 & 1.055 & 1.080 & 0.438 & 0.332 & -0.251 & +0.289 & -0.103 & +0.081 & -0.022 \\
\hline 112.00 & 537 & 206 & 1.843 & 0.779 & 0.585 & 0.270 & -0.341 & +0.141 & -0.113 & +0.048 & -0.069 \\
\hline \multicolumn{12}{|c|}{ The slopes of the mound. Height of the grass was 5 to $10 \mathrm{~cm}$} \\
\hline 110.00 & 138 & 137 & 0.422 & 0.695 & 0.205 & 0.325 & 0.197 & +0.424 & -0.096 & +0.148 & +0.027 \\
\hline 110.50 & 112 & 158 & 0.349 & 0.477 & 0.159 & 0.195 & 0.197 & +0.272 & -0.086 & +0.107 & +0.027 \\
\hline 111.00 & 162 & 124 & 0.326 & 0.3 & 0.114 & 0.109 & 0.184 & +0.184 & -0.064 & +0.064 & -0.006 \\
\hline 111.50 & 169 & 118 & 0.355 & 0.358 & 0.154 & 0.133 & -0.21 & +0.234 & -0.089 & +0.088 & -0.014 \\
\hline 112.00 & 144 & 144 & 0.384 & 0.406 & 0.159 & 0.139 & -0.247 & +0.255 & -0.01 & +0.091 & -0.001 \\
\hline 112.50 & 146 & 137 & 0.347 & 0.381 & 0.138 & 0.137 & -0.256 & +0.246 & -0.098 & +0.096 & -0.004 \\
\hline 113.00 & 125 & 122 & 0.297 & 0.291 & 0.12 & 0.12 & -0.227 & +0.196 & -0.09 & +0.082 & -0.002 \\
\hline 113.50 & 115 & 113 & 0.272 & 0.265 & 0.124 & 0.116 & -0.182 & +0.189 & -0.083 & +0.081 & +0.001 \\
\hline 114.00 & 110 & 100 & 0.251 & 0.213 & 0.12 & 0.105 & -0.161 & +0.161 & -0.08 & +0.073 & -0.007 \\
\hline 114.50 & 103 & 108 & 0.277 & 0.288 & 0.123 & 0.132 & -0.202 & +0.207 & -0.008 & +0.01 & +0.005 \\
\hline 115.00 & 120 & 125 & 0.339 & 0.362 & 0.141 & 0.171 & -0.199 & +0.248 & -0.092 & +0.116 & +0.013 \\
\hline 115.50 & 115 & 139 & 0.378 & 0.329 & 0.181 & 0.137 & -0.249 & +0.219 & -0.124 & +0.099 & -0.001 \\
\hline 116.00 & 120 & 111 & 0.34 & 0.245 & 0.151 & 0.109 & -0.257 & +0.17 & -0.108 & +0.078 & -0.018 \\
\hline 116.50 & 95 & 124 & 0.206 & 0.237 & 0.095 & 0.097 & -0.159 & +0.155 & 0.072 & +0.066 & +0.007 \\
\hline 117.00 & 119 & 88 & 0.267 & 0.222 & 0.119 & 0.108 & -0.185 & +0.16 & -0.082 & +0.078 & -0.02 \\
\hline 117.50 & 95 & 107 & 0.268 & 0.285 & 0.137 & 0.134 & -0.168 & +0.207 & -0.085 & +0.096 & +0.009 \\
\hline 118.00 & 91 & 100 & 0.271 & 0.274 & 0.132 & 0.131 & -0.185 & +0.176 & -0.096 & +0.082 & -0.002 \\
\hline 118.50 & 90 & 99 & 0.259 & 0.278 & 0.115 & 0.117 & -0.193 & +0.183 & -0.009 & +0.075 & -0.002 \\
\hline 119.00 & 110 & 68 & 0.27 & 0.242 & 0.122 & 0.112 & -0.184 & +0.158 & -0.087 & +0.075 & -0.026 \\
\hline 119.50 & 612 & 73 & 0.236 & 0.222 & 0.103 & 0.088 & -0.159 & +0.123 & -0.079 & +0.049 & -0.009 \\
\hline 120.00 & 87 & 92 & 0.254 & 0.405 & 0.094 & 0.123 & -0.217 & +0.177 & -0.072 & +0.063 & -0.003 \\
\hline 120.50 & 70 & 132 & 0.247 & 0.253 & 0.05 & 0.081 & -0.245 & +0.114 & -0.041 & +0.044 & +0.014 \\
\hline 121.00 & 57 & 50 & 0.116 & 0.159 & 0.063 & 0.069 & -0.127 & +0.127 & -0.041 & +0.071 & +0.043 \\
\hline
\end{tabular}


Table 6. Cont.

\begin{tabular}{|c|c|c|c|c|c|c|c|c|c|c|c|}
\hline \multirow[t]{2}{*}{ Isoline Height } & \multicolumn{2}{|c|}{$\begin{array}{l}\text { Number of } \\
\text { Deviation }^{a}\end{array}$} & \multicolumn{2}{|c|}{$\begin{array}{c}\text { Maximum } \\
\text { Plane } \\
\text { Deviation, } m^{b}\end{array}$} & \multicolumn{2}{|c|}{$\begin{array}{c}\text { Average of } \\
\text { Plane } \\
\text { Deviation, } \mathrm{m}^{\mathrm{c}}\end{array}$} & \multicolumn{2}{|c|}{$\begin{array}{l}\text { Maximum of } \\
\text { Height } \\
\text { Deviation, } \mathrm{m}^{\mathrm{d}}\end{array}$} & \multicolumn{2}{|c|}{$\begin{array}{c}\text { Average of } \\
\text { Height } \\
\text { Deviation, } m\end{array}$} & \multirow[t]{2}{*}{ Proportional Deviation $^{f}$} \\
\hline & - & + & - & + & - & + & - & + & - & + & \\
\hline \multicolumn{12}{|c|}{ The top of the mound. Height of the grass was 1 to $2 \mathrm{~cm}$} \\
\hline 121.00 & 71 & 151 & 0.468 & 0.443 & 0.260 & 0.240 & -0.297 & +0.055 & -0.107 & +0.031 & -0.013 \\
\hline 120.50 & 153 & 183 & 0.396 & 0.754 & 0.111 & 0.310 & -0.070 & +0.101 & -0.021 & +0.048 & +0.017 \\
\hline 120.00 & 86 & 251 & 0.373 & 0.466 & 0.148 & 0.269 & -0.042 & +0.091 & -0.018 & +0.051 & +0.033 \\
\hline 119.50 & 151 & 225 & 0.274 & 0.694 & 0.114 & 0.238 & -0.048 & +0.125 & -0.018 & +0.044 & +0.019 \\
\hline 119.00 & 205 & 395 & 0.736 & 0.585 & 0.256 & 1.228 & -0.197 & +0.419 & -0.033 & +0.114 & +0.064 \\
\hline 118.50 & 107 & 490 & 0.647 & 2.373 & 0.302 & 0.804 & -0.235 & +0.196 & -0.106 & +0.074 & +0.042 \\
\hline 121.00 & 71 & 151 & 0.468 & 0.443 & 0.260 & 0.240 & -0.297 & +0.055 & -0.107 & +0.031 & -0.013 \\
\hline 120.50 & 153 & 183 & 0.396 & 0.754 & 0.111 & 0.310 & -0.070 & +0.101 & -0.021 & +0.048 & +0.017 \\
\hline 120.00 & 86 & 251 & 0.373 & 0.466 & 0.148 & 0.269 & -0.042 & +0.091 & -0.018 & +0.051 & +0.033 \\
\hline 119.50 & 151 & 225 & 0.274 & 0.694 & 0.114 & 0.238 & -0.048 & +0.125 & -0.018 & +0.044 & +0.019 \\
\hline 119.00 & 205 & 395 & 0.736 & 0.585 & 0.256 & 1.228 & -0.197 & +0.419 & -0.033 & +0.114 & +0.064 \\
\hline 118.50 & 107 & 490 & 0.647 & 2.373 & 0.302 & 0.804 & -0.235 & +0.196 & -0.106 & +0.074 & +0.042 \\
\hline 121.00 & 71 & 151 & 0.468 & 0.443 & 0.260 & 0.240 & -0.297 & +0.055 & -0.107 & +0.031 & -0.013 \\
\hline 120.50 & 153 & 183 & 0.396 & 0.754 & 0.111 & 0.310 & -0.070 & +0.101 & -0.021 & +0.048 & +0.017 \\
\hline 120.00 & 86 & 251 & 0.373 & 0.466 & 0.148 & 0.269 & -0.042 & +0.091 & -0.018 & +0.051 & +0.033 \\
\hline 119.50 & 151 & 225 & 0.274 & 0.694 & 0.114 & 0.238 & -0.048 & +0.125 & -0.018 & +0.044 & +0.019 \\
\hline 119.00 & 205 & 395 & 0.736 & 0.585 & 0.256 & 1.228 & -0.197 & +0.419 & -0.033 & +0.114 & +0.064 \\
\hline 118.50 & 107 & 490 & 0.647 & 2.373 & 0.302 & 0.804 & -0.235 & +0.196 & -0.106 & +0.074 & +0.042 \\
\hline
\end{tabular}

${ }^{*}$ Explanation of the superscripts in the table: ${ }^{a}$ number of negative $(-\mathrm{N})$ and positive $(+\mathrm{N})$ derivation, ${ }^{\mathrm{b}}$ maximum of negative $(-\Delta)$ and positive $(+\Delta)$ plane derivation, ${ }^{c}$ average of negative $\left(\sum-\Delta /-\mathrm{N}\right)$ and positive $\left(\sum+\Delta /+\mathrm{N}\right)$ plane derivation, ${ }^{\mathrm{d}}$ maximum of negative $\left(-\Delta \mathrm{z}\right.$ max) and positive $\left(+\Delta \mathrm{z}\right.$ max) height derivation, ${ }^{\mathrm{e}}$ average of negative $\left(\sum-\Delta \mathrm{z} / \mathrm{N}_{\mathrm{z}}\right)$ and positive $\left(\sum+\Delta \mathrm{z} / \mathrm{N}_{\mathrm{z}}\right)$ height derivation, and ${ }^{\mathrm{f}}$ ratio of average positive/negative derivation and number of positive/negative derivation $\left(\frac{+\Delta}{-\Delta}\right) /\left(\frac{\mathrm{N}+}{\mathrm{N}-}\right)$.

\section{Conclusions}

1. The "Circle_3p" computer program designed by Artūras Bautrènas, an associate professor of the Department of Cartography and Geoinformatics, employs the classical method of Delaunay and ensures a consistent systemic selection of points.

2. The use of "Circle 3p" for the analysis of aerial photographs of the Lepelionys Mound has shown that the program needs to be improved by adding elements for the correction of the isolines.

3. A comparison of the results of the geodetic measurements and the UAV images, showed that the best overlaps of surface microform isolines are on steep slopes. On the flat top of the mound surface, microform variance makes up 0.7 to $1.0 \mathrm{~m}$. This is due to the rare density of the interpolation points calculated by the program "Circle_3p". The variance of the isolines at the foot of the mound reaches 0.45 to $0.7 \mathrm{~m}$ (medium-height grass) and 0.95 to $1.35 \mathrm{~m}$ (high grass). The study has shown that external factors have a significant influence on the identification of the mound relief microforms.

4. The research related to the GCPs position and shows that five GCPs arranged at the edges and the center of the object give the best accuracy as compared with other variations (three on the top, four on the edge, and ten GCPs).

5. The unnatural curvature of isolines in the UAV 3D model, resulting in the abundance of unnatural surface microforms, is due to the interpolation techniques used to determine the isoline position, specifically the calculation of the interfaces between numerous point pairs.

Author Contributions: A.Č.: conceptualization, methodology, visualization, writing-original draft, writing-review \& editing. A.B.: data curation, formal analysis, investigation, validation. L.B.: investigation, software, visualization. D.O.: investigation, software, validation. 
Funding: This research received no external funding.

Conflicts of Interest: The authors declare no conflict of interest.

\section{References}

1. Jones, R.J.A.; Evans, R. Soil and crop marks in the recognition of archaeological sites by air photography. In Aerial Reconnaissance for Archaeology; Wilson, D.R., Ed.; The Council for British Archaeology: London, UK, 1975; pp. 1-11.

2. Remondino, F.; El-Hakim, S. Image-based 3D modelling, a review. Photogramm. Rec. 2006, 21, $269-291$. [CrossRef]

3. Parcaks, S.H. Satellite Remote Sensing for Archaeology; Routledge: London, UK; New York, NY, USA, 2009; p. 312.

4. Bäumker, M.; Przybilla, H.-J. Investigations on the accuracy of the navigation data of unmanned aerial vehicles using the example of the system microcopter. Arch. Photogramm. Remote Sens. Spat. Inf. Sci. 2011, 38, 113-118.

5. Deseilligny, M.; De Luca, L.; Remondino, F. Automated image-based procedures for accurate artifacts 3D modeling and orthoimages. In Proceedings of the XXIIIth International CIPA Simposium, Prague, Czech Republic, 12-16 September 2011; pp. 291-299.

6. Chiabrando, F.; Nex, F.; Piatti, D.; Rinaudo, F. UAV and RPV systems for photogrammetric surveys in archaeological areas, two tests in the Piedmont Region (Italy). J. Archaeol. Sci. 2011, 38, 697-710. [CrossRef]

7. Lasaponara, R.; Masini, N. Satellite remote sensing in archaeology, past, present and future perspectives. J. Archaeol Sci. 2011, 38, 1995-2002. [CrossRef]

8. Lasaponara, R.; Masini, N. (Eds.) Satellite Remote Sensing: A New Tool for Archaeology; Springer: Heidelberg, Germany, 2012; p. 364.

9. Lasaponara, R.; Masini, N. Satellite synthetic aperture radar in archaeology and cultural landscape: An overview. Archaeol. Prospect. 2013, 20,71-78. [CrossRef]

10. Nex, F.; Remondino, F. UAV for 3D mapping applications, a review. Appl. Geomat. 2013, 6, 1-15. [CrossRef]

11. Hugenholtz, C.H.; Whitehead, K.; Brown, O.W.; Barchyn, T.E.; Moorman, B.J.; LeClair, A.J.; Riddell, K.; Hamilton, T. Geomorphological mapping with a small unmanned aircraft system (SUAS), feature detection and accuracy assessment of a photogrammetrically-derived digital terrain model. Geomorphology 2013, 194, 16-24. [CrossRef]

12. Whitehead, K.; Hugenholtz, C.H. Remote sensing of the environment with small unmanned aircraft systems (UAS): A review of progress and challenges. J. Unmanned Veh. Syst. 2014, 2, 69-85. [CrossRef]

13. Whitehead, K.; Hugenholtz, C.H.; Myshak, S.; Brown, O.W.; LeClair, A.J.; Tamminga, A.; Barchyn, T.E.; Moorman, B.J.; Eaton, B. Remote sensing of the environment with small unmanned aircraft systems (UAS): Scientific and commercial applications. J. Unmanned Veh. Syst. 2014, 2, 86-102. [CrossRef]

14. Themistocleous, K.; Agapiou, A.; Cuca, B.; Hadjimitsis, D.G. Unmanned aerial systems and spectroscopy for remote sensing applications in archaeology. Int. Arch. Photogramm. Remote Sens. Spati. Inf. Sci. 2015, XL-7/W3, 1419-1423. [CrossRef]

15. Hadjimitsis, D.G.; Themistocleous, K.; Agapiou, A. Monitoring Archaeological Site Landscapes in Cyprus using multi-temporal atmospheric corrected image data. Int. J. Archit. Comput. 2009, 7, 121-138. [CrossRef]

16. Agapiou, A.; Hadjimitsis, D.G.; Themistocleous, K.; Papadavid, G.; Toulios, L. Detection of archaeological crop marks in Cyprus using vegetation indices from Landsat TM/ETM+ satellite images and field spectroscopy measurements. Proc. SPIE 2010, 7831, 78310V.

17. Ruzgienè, B.; Berteška, T.; Gečytè, S.; Jakubauskienė, E.; Aksamitauskas, V.Č. The surface modelling based on UAV photogrammetry and qualitative estimation. Measurement 2015, 73, 619-627. [CrossRef]

18. Sužiedelytė-Visockienè, J.; Bručas, D.; Bagdžiūnaitè, R.; Puzienè, R.; Stanionis, A.; Ragauskas, U. Remotely-piloted aerial system for photogrammetry: Orthoimage generation for mapping applications. Geografie 2016, 121, 349-367.

19. Campana, S. Drones in archaeology. State-of-the-art and future perspectives. Archaeol. Prospect. 2017, 24, 275-296. [CrossRef]

20. Traviglia, A.; Torsello, A. Landscape pattern detection in archaeological remote sensing. Geosciences 2017, 7, 128. [CrossRef] 
21. Masini, N.; Marzo, C.; Manzari, P.; Belmonte, A.; Sabia, C.; Lasaponara, R. On the characterization of temporal and spatial patterns of archaeological crop-marks. J. Cult. Herit. 2018, 32, 124-132. [CrossRef]

22. Cowley, D.C.; Moriarty, C.H.; Geddes, G.; Brown, G.L.; Wade, T.; Nichol, C.J. UAVs in context: Archaeological airborne recording in a national body of survey and record. Drones 2018, 56, 2. [CrossRef]

23. Tapete, D. Remote sensing and geosciences for archaeology. Geosciences 2018, 7, 41. [CrossRef]

24. Konstantinos, K.G.; Soura, K.; Koukouvelas, I.K.; Argyropoulos, N.G. UAV vs classical aerial photogrammetry for archaeological studies. J. Archaeol. Sci. Rep. 2017, 14, 758-773.

25. Sanz-Ablanedo, E.; Chandler, J.H.; Rodríguez-Pérez, J.R.; Ordóñez, C. Accuracy of unmanned aerial vehicle (UAV) and SfM photogrammetry survey as a function of the number and location of ground control points used. Remote Sens. 2018, 10, 1606. [CrossRef]

26. Shahbazi, M.; Sohn, G.; Théau, J.; Menard, P. Development and evaluation of a UAV-photogrammetry system for precise 3D environmental modeling. Sensors 2015, 15, 27493-27524. [CrossRef] [PubMed]

27. Turner, D.; Lucieer, A.; Watson, C. An automated technique for generating georectified mosaics from ultra-high resolution unmanned aerial vehicle (UAV) imagery, based on structure from motion (SFM) point clouds. Remote Sens. 2012, 4, 1392-1410. [CrossRef]

28. Shahbazi, M.; Sohn, G.; Théau, J.; Menard, P. Robust structure-from-motion computation: Application to open-pit mine surveying from unmanned aerial images. J. Unmanned Veh. Syst. 2017, 5, 126-145. [CrossRef]

29. Mian, O.; Lutes, J.; Lipa, G.; Hutton, J.J.; Gavelle, E.; Borghini, S. Accuracy assessment of direct georeferencing for photogrammetric applications on small unmanned aerial platforms. Int. Arch. Photogramm. Remote Sens. Spat. Inf. Sci. 2016, 40, 77-83. [CrossRef]

30. Hugenholtz, C.; Brown, O.; Walker, J.; Barchyn, T.; Nesbit, P.; Kucharczyk, M.; Myshak, S. Spatial accuracy of UAV-derived orthoimagery and topography: Comparing photogrammetric models processed with direct geo-referencing and ground control points. Geomatica 2016, 70, 21-30. [CrossRef]

31. Benassi, F.; Dall'Asta, E.; Diotri, F.; Forlani, G.; Cella, U.M.; Roncella, R.; Santise, M. Testing the accuracy and repeatability of UAV blocks oriented with GNSS-supported aerial triangulation. Remote Sens. 2017, 9, 172. [CrossRef]

32. Forlani, G.; Dall'Asta, E.; Diotri, F.; Cella, U.M.; di Roncella, R.; Santise, M. Quality assessment of DSMs produced from UAV flights georeferenced with on-board RTK positioning. Remote Sens. 2018, 10, 311. [CrossRef]

33. Buivydas, U. The Settlement at the foot of Lepelionys Hill Fort. In Archaeological Research in Lithuania; Lithuanian Archaeological Society: Vilnius, Lithuania, 2006; pp. 65-66.

34. Banytè-Rowell, R.; Baronas, D.; Kazakevičius, V.; Vaškevičiūtè, I.; Zabiela, G. History of Lithuania; Zabiela, G., Ed.; The Lithuanian Institute of History: Vilnius, Lithuania, 2007; Volume 2, p. 518.

35. Jovaiša, E. The Aestii: Genesis; Lithuanian University of Educational Sciences: Vilnius, Lithuania, 2013; Volume 1, p. 379.

36. Jovaiša, E. The Aestii: Evolution; Lithuanian University of Educational Sciences: Vilnius, Lithuania, 2014; Volume 2, p. 351.

37. Viršilienė, J.; Zabiela, G. Revived Mounds; The Lithuanian Institute of History: Vilnius, Lithuania, 2018 ; p. 219.

38. Berni, J.; Zarco-Tejada, P.J.; Suarez, L.; Fereres, E. Thermal and narrowband multispectral remote sensing for vegetation monitoring from an unmanned aerial vehicle. IEEE Trans. Geosci. Remote Sens. 2009, 47, 722-738. [CrossRef]

39. Baluja, J.; Diago, M.P.; Balda, P.; Zorer, R.; Meggio, F.; Morales, F.; Tardaguila, J. Assessment of vineyard water status variability by thermal and multispectral imagery using an unmanned aerial vehicle (UAV). Irrig. Sci. 2012, 30, 511-522. [CrossRef]

40. Bellvert, J.; Zarco-Tejada, P.J.; Girona, J.; Fereres, E. Mapping crop water stress index in a Pinot-Noir vineyard: Comparing ground measurements with thermal remote sensing imagery from an unmanned aerial vehicle. Precis. Agric. 2013, 15, 361-376. [CrossRef]

41. Chisholm, R.A.; Cui, J.; Lum, S.K.Y.; Chen, B.M. UAV LiDAR for below-canopy forest surveys. J. Unmanned Veh. Syst. 2013, 1, 61-68. [CrossRef]

42. Huesca, M.; Merino-de-Miguel, S.; González-Alonso, F.; Martinez, S.; Miguel Cuevas, J.; Calle, A. Using AHS hyper-spectral images to study forest vegetation recovery after a fire. Int. J. Remote Sens. 2013, 34, 4025-4048. [CrossRef] 
43. Knoth, C.; Klein, B.; Prinz, T.; Kleinebecker, T. Unmanned aerial vehicles as innovative remote sensing platforms for high-resolution infrared imagery to support restoration monitoring in cut-over bogs. Appl. Veg. Sci. 2013, 16, 509-517. [CrossRef]

44. Mozas-Calvache, A.T.; Pérez-García, J.L.; Cardernal-Escarcena, F.J.; Delgado, J.; Mata-de-Castro, E. Comparison of low altitude photogrammetric methods for obtaining DEMs and orthoimages of archaeological sites. Int. Arch. Photogramm. Remote Sens. Spat. Inf. Sci. 2012, 39, 577-581. [CrossRef]

45. Erny, G.; Gutierrez, G.; Friedman, A.; Godsey, M.; Gradoz, M. Archaeological topography: Comparing digital photogrammetry taken with unmanned aerial vehicles (UAVs) versus standard surveys with total stations. In Proceedings of the 80th Annual Meeting of the Society for American Archaeology, San Francisco, CA, USA, 15-19 April 2015; p. 409.

46. Mesas-Carracosa, F.-J.; Notario-Garcia, M.D.; Meroño de Larriva, J.E.; García-Ferre, A. An analysis of the influence of flight parameters in the generation of unmanned aerial vehicle (UAV) orthomosaics to survey archaeological areas. Sensors 2016, 16, 1838. [CrossRef]

47. Mian, O.; Lutes, J.; Lipa, G.; Hutton, J.J.; Gavelle, E.; Borghini, S. Direct georeferencing on small unmanned aerial platforms for improved reliability and accuracy of mapping without the need for ground control points. In Proceedings of the International Conference on Unmanned Aerial Vehicles in Geomatics, Toronto, ON, Canada, 30 August-2 September 2015; Volume XL-1/W4, pp. 397-402.

48. Agüera-Vega, F.; Carvajal-Ramirez, F.; Martínez-Carricondo, P. Assessment of photogrammetric mapping accuracy based on variation ground control points number using unmanned aerial vehicle. Measurement 2017, 98, 221-227. [CrossRef]

49. Fryskowska, A.; Kedzierski, M.; Walczykowski, P.; Wierzbicki, D.; Delis, P.; Lada, A. Effective detection of sub-surface archaeological features from laser scanning point clouds and imagery data. Int. Arch. Photogramm. Remote Sens. Spat. Inf. Sci. 2017, 42, 245-251. [CrossRef]

50. Carvajal-Ramírez, F.; Navarro-Ortega, A.D.; Agüera-Vega, F.; Martínez-Carricondo, P.; Mancini, F. Virtual reconstruction of damaged archaeological sites based on unmanned aerial vehicle photogrammetry and 3D modelling: Study case of a southeastern Iberia production area in the Bronze Age. J. Int. Meas. Conf. 2019, 136, 225-236. [CrossRef]

51. Juškaitis, V. Report of Archaeological Research in 2007 of the Ancient Settlement of the Lepelionys Mound (22593, Prienai District); Trakai Historical Museum: Trakai, Lithuania, 2009.

52. Juškaitis, V. The settlement at the foot of the lepelionys hill fort site. In Archaeological Research in Lithuania; The Lithuanian Institute of History: Vilnius, Lithuania, 2007; pp. 73-74.

53. Fang, T.; Piegl, L. Algorithm for Delaunay triangulation and convex hull computation using a sparse matrix. Comput. Aided Des. 1992, 24, 425-436. [CrossRef]

54. Hacigüzeller, P. Collaborative mapping in the age of ubiquitous internet: An archaeological perspective. Digit. Class. Online 2017, 3, 5-16.

55. Perkins, C. Community Mapping. Cartogr. J. 2007, 44, 127-137. [CrossRef]

56. Lee, D. Map Orkney Month: Imagining Archaeological Mappings. Livingmaps Rev. 2016, 1, 1-25.

(C) 2019 by the authors. Licensee MDPI, Basel, Switzerland. This article is an open access article distributed under the terms and conditions of the Creative Commons Attribution (CC BY) license (http://creativecommons.org/licenses/by/4.0/). 